\title{
Three Theoretical Perspectives for Understanding Inter-firm Coordination of Construction Project Supply Chains
}

Eduardo Luis Isatto and Carlos Torres Formoso, (Federal University of Rio Grande do Sul, Brazil)

\begin{abstract}
The success of construction projects is highly dependent on the coordination of a fairly large number of stakeholders, such as client organizations, designers, general contractors, and subcontractors. Each of those stakeholders can both affect and be affected by the way a project is managed, and none of them usually has the power or the ability to coordinate project supply chains. However, there is no comprehensive theoretical foundation for describing or explaining the coordination of construction project supply chains. This paper discusses the role of three different theoretical perspectives for understanding the inter-firm coordination process of project supply chains in the construction industry: the Theory of Coordination, the Transaction Cost Theory and the Language-Action Perspective. Although the combined use of theoretical approaches has been suggested in the literature, an indepth discussion on how they complement each other, based on empirical data, seems to be necessary. The contribution of each theoretical approach is pointed out in the paper, and their complementary role is illustrated in a case study carried out in a petrochemical construction project in Brazil.
\end{abstract}

Keywords: Supply chain management, Inter-firm coordination, Project management, Complexity

\section{Introduction}

In spite of the attention that supply chain management (SCM) has attracted among practitioners and researchers, the translation of its concepts, practices and techniques into the construction industry is still a challenging issue, mostly due to differences that exist between this sector and other industries (O'Brien et al., 2004). SCM originated in industries where demand is predictable, requirements for variety are limited, and volume is high (Christopher, 2000). Most contemporary academic work in this field is concerned with high volume industries, where a large-scale (hence economically powerful) manufacturer is supported by smaller (economically weaker) suppliers or subcontractors, based on long-term relationships (Bresnen, 1996). In fact, it is often assumed that a single company is capable of controlling and even designing its supply chain.

By contrast, construction project supply chains are essentially temporary multi-organizations that are set up with the specific purpose of delivering a construction project. Such supply chains arise at the start of the project, develop, and finally disband as the end of it (Cherns and Bryant, 1984). In such supply chains, inter-firm coordination is a complex task, due to both the large number of firms involved and the lack of knowledge about their individual behavior (Grandori, 1997). Each of those stakeholders can both affect and be affected by the way a project is managed, and none of them usually has the power or the ability to coordinate project supply chains.

Much of the research on construction SCM has addressed the problem of describing construction supply chains or explaining how they are actually managed (O'Brien et al., 2004). One of the difficulties faced by researchers on this task is that distinct and sometimes disconnected theoretical approaches have been proposed for understanding SCM. Each perspective usually considers only a particular and limited aspect of supply chain 
management, thus not being capable of providing a comprehensive description of their structure, nor an adequate explanation of their behavior (Croom et al., 2000; Tan, 2001).

While such a diversity of perspectives may be a remarkable characteristic of novel fields of research, a movement of convergence is expected to occur as those fields evolve and mature (Kuhn, 1962). Indeed, in recent years the simultaneous use of multiple theoretical approaches has been suggested as a means to provide a more complete understanding of construction supply chains. O'Brien, London and Vrijhoef (2004) have proposed an interdisciplinary research agenda for construction SCM that combines elements of operations management, analytic modeling, and industrial organization theory, while Vrijhoef, Koskela and Voordijk (2003) have identified Transaction Cost Theory, Operations Management, Language/Action Perspective, and Network Theory as potential candidates for devising a comprehensive theoretical framework for this field. However, those papers have simply suggested the combined use of sets of theoretical approaches. None of them has made an in-depth discussion on how they complement each other, based on empirical data.

This paper discusses the limited role of three different theoretical perspectives for understanding the inter-firm coordination process of project supply chains in the construction industry: the Theory of Coordination (TC), the Transaction Cost Theory (TCT) and the Language-action Perspective (LAP). These approaches are discussed in the paper, and their limitations and complementarities are illustrated in the description of a case study carried out in a petrochemical construction project in Brazil.

\section{Theoretical Approaches for Inter-firm Coordination}

\section{Core Dimensions of Inter-firm Coordination}

According to Stadtler (2005), supply chain management involves the coordination of three main flows: materials, information and financial flows. Value (or product) flows are often regarded as the main purpose of supply chains since they are the means by which value is generated and delivered to the customers (Johnston, 1995; Ballou et al., 2000). They usually comprise the flows of materials or components being processed, but may also include information, since most products are a combination of physical goods and services. The role of financial flows is to support the cooperation that is necessary for the production flows to occur between supply chain members (Stadtler, 2005).

\begin{tabular}{|c|c|c|c|}
\hline Dimension & Flow type & Purpose & Main problem addressed \\
\hline Production & $\begin{array}{l}\text { Products } \\
\text { (materials and } \\
\text { information) }\end{array}$ & $\begin{array}{l}\text { Deliver value to the } \\
\text { client }\end{array}$ & $\begin{array}{l}\text { Coordinate the flow of products (goods } \\
\text { or services) among supply chain } \\
\text { members }\end{array}$ \\
\hline Economic & Financial & $\begin{array}{l}\text { Achieve and sustain } \\
\text { cooperation among } \\
\text { supply chain } \\
\text { members }\end{array}$ & $\begin{array}{l}\text { Coordinate transactions (exchanges) } \\
\text { between supply chain members by } \\
\text { incentive alignment }\end{array}$ \\
\hline Social & $\begin{array}{l}\text { Information (for } \\
\text { coordination) }\end{array}$ & $\begin{array}{l}\text { Coordinate actions } \\
\text { among autonomous } \\
\text { actors }\end{array}$ & $\begin{array}{l}\text { Coordinate the collective action of } \\
\text { supply chain members }\end{array}$ \\
\hline
\end{tabular}

Table 1 The three dimensions of inter-organizational coordination of supply chains

In situations that involve discrete transactions, understanding value and financial flows may be enough, since the exchange between money and products are easy to evaluate (Macneil, 1978). However, most exchanges in construction projects are not so simple, demanding an intense coordination effort among supply chain members. This places the flow of information as one of the pivotal elements to promote the coordination of the collective action among supply chain members (Winograd and Flores, 1985; Crowston, 1991; Denning and MedinaMora, 1995; Ballou et al, 2000), both by triggering their action as well as by creating a

Isatto, E L and Formoso, C T (2011) 'Three theoretical perspectives for understanding inter-firm coordination of construction project supply chains', Australasian Journal of Construction Economics and Building, 11 (3) 1-17 
common background among people and organizations that is vital for mutual understanding (Winograd and Flores, 1985).

Therefore, each of those flows encompasses a specific purpose that should be considered in order to describe the coordination among supply chain members. Each one defines a distinct and important dimension of inter-firm coordination: the production, the economic and the social dimensions (Table 1).

\section{Production Dimension: The Theory of Coordination}

The production dimension is concerned with both the definition of the necessary tasks to be carried out in the project and the further assignment of those tasks among supply chain members, and the definition of the means to be used to coordinate the dependences among those members. While in other industries those actions occur only a limited number of times, they are much more important in construction due to the unique and temporary nature of project supply chains. The Theory of Coordination (TC), originally proposed by Crowston (1991), and built mostly on the work of March and Simon (1958) and Thompson (1967), is particularly suitable for understanding this dimension.

March and Simon (1958) suggested two forms of specialization to guide the process of task decomposition and assignment: (a) specialization by process, grouping people that know only a particular process (e.g. engineering, design, procurement); and (b) specialization by purpose, grouping people that work only in a particular part of the product (e.g. subcontractors that work in the same stage of the project). Thompson (1967) proposed a framework to bridge each type of interdependence (pooled, sequential and combined) and the most appropriate solution in terms of coordination mechanisms (standardization, rules or mutual adjustment) (see Table 2).

\begin{tabular}{|l|l|l|}
\hline & \multicolumn{1}{|c|}{ Kind of interdependence } & \multicolumn{1}{c|}{$\begin{array}{c}\text { Coordination mechanism } \\
\text { Sooles: }\end{array}$} \\
\hline each actor contributes to and \\
depend on the whole
\end{tabular}

Table 2 Kinds of interdependence and coordination mechanisms (based on Thompson, 1967)

TC aims to understand why coordination is necessary and how coordination is actually achieved. According to Malone and Crowston (1994), coordination is "the act of managing dependences among activities", involving the design and implementation of specific tasks aimed at this purpose. TC proposes that such tasks can be generalized in the form of coordination methods that are able to solve specific coordination problems, and that adequate coordination methods exist for every kind of coordination problem (Crowston, 1991). Distinct kinds of coordination problems may arise according to the kind of taskresource dependence that is involved, as shown in Table 3.

There are some clear connections between the Theory of Coordination and the framework proposed by Thompson (1967). Whereas sequential interdependences arise from flow dependences of multiple tasks that use or create a non-shareable resource, pooled interdependences occur when multiple tasks use or create the same shareable and reusable resources. By contrast, reciprocal interdependences cannot be easily modeled, making it

Isatto, E L and Formoso, C T (2011) 'Three theoretical perspectives for understanding inter-firm coordination of construction project supply chains', Australasian Journal of Construction Economics and Building, 11 (3) 1-17 
necessary to adopt the coordination mechanism of mutual adjustment and teams, since standardization, rules and plans tend to be ineffective in those situations.

\begin{tabular}{|c|c|}
\hline Type of task-resource dependence & Coordination problems \\
\hline $\begin{array}{l}\text { Flow dependence (one task uses a } \\
\text { resource created by another) }\end{array}$ & $\begin{array}{l}\text { Resources must be made available by one task when it } \\
\text { is needed by another (prerequisite condition) } \\
\text { Quality of resources must be adequate for use (usability } \\
\text { condition) } \\
\text { Resources must be available at the right place } \\
\text { (availability) }\end{array}$ \\
\hline $\begin{array}{l}\text { Multiple tasks create the same } \\
\text { resource }\end{array}$ & $\begin{array}{l}\text { Shareable resources: eliminate redundant efforts or } \\
\text { negotiate the object, choosing the best one } \\
\text { Non shareable and reusable resources: combine the } \\
\text { outcomes of the tasks (integrate) } \\
\text { Non-shareable and consumable resources: select one or } \\
\text { seek economies of scale by merging tasks }\end{array}$ \\
\hline Multiple tasks use the same resource & $\begin{array}{l}\text { Shareable resources: no conflict arises } \\
\text { Non-shareable and reusable resources: schedule use of } \\
\text { resources } \\
\text { Non-shareable and consumable resources: favour one } \\
\text { task instead of another }\end{array}$ \\
\hline Task-subtask dependence & $\begin{array}{l}\text { Create and assign sub-tasks } \\
\text { Manage dependences among sub-tasks } \\
\text { Assure that sub-tasks include all the content of the } \\
\text { original task (i.e. nothing if left unassigned) }\end{array}$ \\
\hline
\end{tabular}

Table 3 Types of dependences and corresponding coordination problems (based on Crowston, 1991 and Crowston and Osborn, 1995)

Therefore, the effects of task decomposition on the dependences between subtasks play an important role in framing the TC into a dynamic context, as the process of task decomposition and assignment can be itself highly dynamic. If subtasks are well known in advance, it is possible to create a plan for performing the task, while a more adaptive process is required when there is more uncertainty about the subtasks to be carried out (Crowston, 1991).

As tasks are decomposed into subtasks and assigned to different actors, new dependences will arise (Crownston, 1991). The choice of a specific type of specialization can greatly affect the need for further coordination. It is expected that the specialization by process will generate flow dependences among actors because each actor is responsible for a single part of the whole process, and specialization by purpose will demand a greater use or creation of common resources.

A serious limitation of $\mathrm{TC}$ is that it assumes that actors are essentially cooperative, i.e. there are usually no conflicts between their goals and, when asked to do something, they do it (Crowston, 1991). This greatly constrains its application to inter-organizational contexts. While the motivation for cooperation in an inter-organizational context is largely affected by the possibility of achieving economic benefits, this cannot be considered as the only relevant factor for cooperation among firms, since "cooperation is jointly determined by social factors and incentive alignment" (Williamson, 1985).

\section{Economic Dimension: The Transaction Cost Theory}

The problem of governance is particularly relevant in the case of a construction project supply chain, as it relies on the establishment of contractual relationships that may not be recurrent, thus affecting the willingness of its members to cooperate (Axelrod, 2000). 
Moreover, contracting costs tend to be affected by uncertainty and the degree of asset specificity that is involved in a project.

The first step to bridge economic and behavioural aspects was made by Ronald Coase in 1937 by proposing the Transaction Cost Theory ${ }^{1}$ (TCT), which was further extended by Williamson (1985). It was successfully used by Winch (2001) as a conceptual framework to analyze construction supply chains, particularly for explaining the governance of the construction projects.

TCT is based on two main assumptions: (a) economic transactions occur in a context characterized by the presence of opportunism - "self-interest seeking with guile" (Williamson, 1985); and (b) human agents are subject to bounded rationality ${ }^{2}$ - their behaviour is "intendedly rational, but only limitedly so" (Simon, 1961, p. xxiv). Therefore, it is not possible to anticipate all problems that can arise in a contract, being necessary to devise a governance structure to avoid or to solve occasional disputes in the execution of a contract.

According to Williamson (1985), the frequency of transactions (recurrent or occasional) and the degree of asset specificity involved (non-specific, mixed or idiosyncratic) are the features that will dictate the most adequate governance structure to be adopted for the transaction in terms of minimizing overall transaction costs (Table 4). In transactions that involve nonspecific assets, the market (classical contracting) tends to be the most adequate governance form. By contrast, highly idiosyncratic and recurrent transactions should be governed by a unified governance (i.e. inside the firm). In between there is a continuum of governance structures, such as trilateral governance (neoclassical contracting) and bilateral governance (relational contracting) (Williamson, 1985).

\begin{tabular}{|c|c|c|c|}
\hline \multirow{2}{*}{ Frequency } & Non specific & Mixed & Idiosyncratic \\
\cline { 2 - 4 } Occasional & $\begin{array}{c}\text { Market governance } \\
\text { (classical contracting) }\end{array}$ & $\begin{array}{c}\text { Trilateral governance } \\
\text { (neoclassical contracting) }\end{array}$ & $\begin{array}{c}\text { Trilateral governance } \\
\text { (neoclassical contracting) } \\
\text { or Unified governance }\end{array}$ \\
\hline Recurrent & $\begin{array}{c}\text { Market governance } \\
\text { (classical contracting) }\end{array}$ & $\begin{array}{c}\text { Bilateral governance } \\
\text { (relational contracting) }\end{array}$ & Unified governance \\
\hline
\end{tabular}

Table 4 Alternative governance structures (based on Williamson, 1985)

Classical contracting explicitly recognizes the possibility of an opportunistic behavior from the other party, but does not take into consideration the presence of bounded rationality. These assumptions are reasonable in the context of non-specific assets (commodities), in which the number of possible alternatives for the other party is very large, or in situations characterizes by low level of uncertainty. In both situations, the effects of bounded rationality are not expressive, and then tends not to affect contract execution.

By contrast, relational contracting explicitly assumes the presence of bounded rationality, and relies on mutual adjustment to overcome its effects. It often reveals to be the most

It is also known as Transaction Cost Economics

The concept of bounded rationality has been coined by Simon (1961) to refer to the limitations of rational decision-making, based on the assumption that the ability for an individual to make a completely rational decision is always limited by the information that is accessible, the finite amount of time available, and cognitive limitations of the human mind. An interesting discussion about the subtleties and limitations on the concept of bounded rationality can be found in Gigerenzer and Selten (2001).

Isatto, E L and Formoso, C T (2011) 'Three theoretical perspectives for understanding inter-firm coordination of construction project supply chains', Australasian Journal of Construction Economics and Building, 11 (3) 1-17 
adequate governance structure in situations characterized by recurring transactions that are supported by investments of mixed kind, since the recurrence of transactions justifies the existence of a highly specialized governance structure. In such situations, long-term relationships are driven by trust and mutual interest, and opportunism is assumed to be absent (Williamson, 1985). Therefore, original agreement often looses its importance as the main reference for the relationship, as new rules and practices are mutually agreed by both parties during contract execution, and the relationship tends to evolve towards partnering as opportunistic behavior from the other party becomes less probable due to the frequency of the transactions and the possibility of new ones (Axelrod, 1984).

However, neither classical nor relational contracting is able to cope with both opportunism and bounded rationality. In those situations, the neoclassical contracting scheme (trilateral contracting) arises as an adequate governance structure, since a third-party assistance (arbitration) is introduced for resolving disputes and evaluating performance (Williamson, 1985).

The relevance of the TCT for explaining the economic coordination of construction project supply chains arise from the fact that most of the linkages that tie firms together are contracts. Additionally, whereas the classical contracting (market governance) is adopted in most of the situations, this is usually due to unawareness of uncertainty and the possibility of opportunistic actions by the other part, as well as the wrong assumption that justice is fast, cheap and reliable enough to enforce contract execution through its completion (Williamson, 1985).

\section{Social Dimension: The Language-Action Perspective}

Once the contractual relationships are established, there is a need to manage the collective work by coordinating the actions of supply chain members. Task subdivision, their assignments to individuals, and the subsequent coordination of dependences among them can only in part solve the coordination problem. However, as tasks are fragmented in a more detailed level of subdivision, complexity increases, and so the effects of bounded rationality. Subtasks and dependences are difficult to anticipate in advance. As a result, neither TC nor TCT are able to explain how the collaboration among the members of supply chain actually happens in such context, especially when high degrees of interdependence and autonomy exist, such as in most construction projects. Håkansson and Ford (2003) point out that, in those situations, the deliberate approach for coordinating supply chains often shows to be ineffective, as the behavior of the supply chain cannot be induced or anticipated by a single company but rather is the result of simultaneous and parallel actions of their members (Choi et al., 2001).

In this context, the Language-Action Perspective (LAP), proposed by Flores (1982), arises as a promising theoretical framework for dealing with the social dimension of supply chain coordination. In fact, it has been argued that LAP can be successfully used for explaining the management of commitments in production planning and control in the construction industry (Vrijhoef et al., 2001; Macomber and Howell, 2003).

Flores (1982) pointed out that language can be used to create a mutual orientation among different actors, in a kind of social action which, in turn, results in changes in the real world: "when we speak we engage in commitments, which in turn generate action". In opposition to the rationalistic tradition that takes language as a representation - a carrier of information, Winograd and Flores (1986) suggests that language can also acts as a vehicle for requests and commissives, directed towards explicit cooperative action. This kind of performative conversation (and the resulting commitments) relies on a "consensual domain", which is the result of informative conversation, i.e. the exchange of knowledge, and that creates a common background that assures meaning to the language. In spite of the fact that both kinds of conversation - performative and informative - are equally important and

Isatto, E L and Formoso, C T (2011) 'Three theoretical perspectives for understanding inter-firm coordination of construction project supply chains', Australasian Journal of Construction Economics and Building, 11 (3) 1-17 
complementary, the Language-Action Perspective focuses explicitly on the language for action.

As a consequence, information systems can be understood at a more abstract level, where the flow of information arises to support commitments that must be set up and coordinated in order to generate desired actions (Flores, 1982; Winograd and Flores, 1986; van Reijswoud and Dietz, 1999). Thus, the effective coordination of actions can be considered as the same as the effective management of commitments, and the work progress can be traced by watching speech acts in the communications of those coordinating (Flores, 1982).

Denning and Medina-Mora (1995) suggest that commitments can be viewed as workflow loops in which one party (the performer) promises to satisfy a request of the other (the customer). Every loop is made of four phases, and the completion of each phase occurs by the utterance of a specific kind of sentence by the performer or the customer (Figure 1). In the request phase, the customer makes a request to the performer or accepts an offer made by the performer ("I request"). The negotiation phase occurs when the customer and performer negotiate on the conditions that will satisfy the customer, culminating in the performer's promise (implied contract) to fulfill those conditions ("I promise"). Then the performance phase follows, in which the performer does the work and ends by declaring that it is done ("I am done"). The loop ends with the satisfaction phase, in which the customer accepts the work and declares satisfaction. Satisfaction means that the implied contract has been fulfilled; it means neither gratification nor a psychological report about the customer ("I am satisfied").

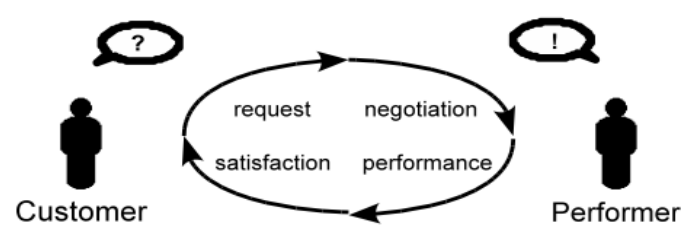

Figure 1 The commitment loop (adapted from Denning and Medina-Mora, 1995)

However, the incompleteness of commitment loops cannot be regarded as the causes for breakdowns. The way commitment loops are interconnected to form business processes also play an important role in coordinating actions. In fact, every organization can be depicted as a map of interconnected commitment loops, which can be used for designing work processes and supporting information technologies, managing commitments up to completion, and measuring productivity in order to avoid breakdowns (Flores, 1982). Thus, the effectiveness of the coordination of collective action relies both on the completeness of commitment loops and on the structure of business processes as a chain of interconnected commitment loops.

\section{Research Method}

Two descriptive case studies were carried out in different projects of the same general contractor. This company had been mainly involved in industrial, commercial, and health care projects for private clients. Those projects usually had a high level of complexity, according to the definition proposed by Williams (1999): there was a very large number of tasks and interdependences, and uncertainty was very high, mostly due to the overlapping between design and production stages. The role of the company in those projects was both carrying out construction activities and partially coordinating the design process. It was the main connection between the main project stakeholders: owner, most designers, and subcontractors. For that reason, it was considered in this investigation as the focal company of the project supply chain. As suggested by Lambert and Cooper (2000), choosing a focal

Isatto, E L and Formoso, C T (2011) 'Three theoretical perspectives for understanding inter-firm coordination of construction project supply chains', Australasian Journal of Construction Economics and Building, 11 (3) 1-17 
company is necessary in order to define which members of the supply chain should receive managerial attention and resources.

In this article, one case study was chosen to illustrate the limitations and complementarities of the three theoretical approaches for understanding project supply chain. This project consisted of the design and construction of a new laboratory $\left(1607 \mathrm{~m}^{2}\right)$ and the refurbishment of an existing one $\left(832 \mathrm{~m}^{2}\right)$ for a petrochemical company, in the South of Brazil. There were clearly two different stages in the project, regarding the coordination process: (a) in the first eight weeks, the supply chain members worked mostly according to the coordination assumptions and coordination structure that was initially established; and (b) after facing several coordination problems, some important changes were introduced in the coordination process. The duration of the case study was 8 months.

The aim of this case study was to understand how the coordination of the construction project supply chain was carried out, using the three theoretical approaches described in the previous section. Table 6 presents a set of descriptive factors that were used for guiding data collection, and the multiple sources of evidence that were used.

\section{Illustrative Case Study}

Phase 1

Three departments of the client organization were directly involved in the project: the marketing department, as the main user of the facilities; the maintenance department, responsible for maintaining the facilities; and the financial department, the main decision makers in terms of capital investment. The client organization adopted the strategy of specialization by process, breaking down the project ("installing a lab") into three major subtasks: "design lab", "build lab" and "install equipment" (Figure 2). They were assigned to the architect, the GC and the maintenance department, respectively. Thus, the task-resource dependences that arose were mainly of the flow type. The intention of the client company was to coordinate the information flow about user requirements and architectural design definitions. Design coordination meetings were considered to be necessary to assure that such information was properly passed on to the design team.

By contrast, the GC decided to break down the overall task of designing and producing subsystems, adopting the strategy of specialization by purpose. Each subsystem was assigned to a different specialty subcontractor (Figure 2). The intention behind that strategy was to simplify the coordination among design and production for the main subsystems (e.g. foundations, HVAC, and precast concrete structure) by delegating that kind of coordination to different subcontractors. However, the general contractor kept the role of coordinating the work of all specialty subcontractors, being responsible for coordinating the information flow of architectural decisions to subcontractors, as well as the flow dependences among the sub-systems on site. That situation posed a new coordination problem since the tasks to be carried out by distinct designers were supposed to be relying upon the same common resource (drawings and specifications), which were used and modified by each of them as a result of their individual work.

The responsibility for coordinating the delivery of the building from the general contractor for the installation of equipment remained with the client, and would happen only after the final delivery of the building.

Even considering that most of the task assignments involved assets with a high degree of specificity, a classical contracting scheme (market governance) between the client and the GC was initially adopted, due the intention of the former to have strict control over the total cost of the project. This contract also established high penalties for project delays. By contrast, most of the contracts between the GC and some specialty subcontractors were far

Isatto, E L and Formoso, C T (2011) 'Three theoretical perspectives for understanding inter-firm coordination of construction project supply chains', Australasian Journal of Construction Economics and Building, 11 (3) 1-17 
more flexible, due to partnership relationships that they had in a number of previous projects. Bilateral governance structures (relational contracting) were adopted, as the decision of purchasing entire subsystems resulted in much less control over the process due to the high degree of specialization involved. Classical contracting was adopted by the GC for hiring a few labor-only subcontractors, to whom some minor works were assigned.

\begin{tabular}{|c|c|c|}
\hline $\begin{array}{l}\text { Theoretical } \\
\text { approach }\end{array}$ & Descriptive factors & Sources of evidence \\
\hline \multirow[t]{3}{*}{$\begin{array}{l}\text { Theory of } \\
\text { Coordination }\end{array}$} & $\begin{array}{l}\text { - Strategy for breaking down } \\
\text { processes and assigning tasks to } \\
\text { supply chain members }\end{array}$ & $\begin{array}{l}\text { - Participant observation in } 28 \text { medium- } \\
\text { term planning meetings, and in } 9 \text { design } \\
\text { meetings } \\
\text { - Analysis of long and short-term } \\
\text { production plans ( } 28 \text { weeks), and design } \\
\text { brief } \\
\text { - Project extranet data and e-mails }\end{array}$ \\
\hline & $\begin{array}{l}\text { - Dependencies between supply } \\
\text { chain members: types of task- } \\
\text { resource dependencies between } \\
\text { members, coordination tasks, } \\
\text { existing coordination problems }\end{array}$ & $\begin{array}{l}\text { - Participant observation in } 28 \text { medium- } \\
\text { term planning meetings, and in } 9 \text { design } \\
\text { meetings } \\
\text { - Project extranet data ( } 8 \text { weeks) and e- } \\
\text { mails }\end{array}$ \\
\hline & $\begin{array}{l}\text { - Structure of the coordination } \\
\text { system: coordination mechanisms } \\
\text { adopted, existing interactions } \\
\text { between them, effectiveness in } \\
\text { managing dependencies }\end{array}$ & $\begin{array}{l}\text { - Participant observation in } 28 \text { medium- } \\
\text { term planning meetings, and in } 9 \text { design } \\
\text { meetings } \\
\text { - Analysis of long, medium and short- } \\
\text { term production plans ( } 28 \text { weeks) } \\
\text { - Project extranet data ( } 8 \text { weeks) and e- } \\
\text { mails }\end{array}$ \\
\hline \multirow[t]{2}{*}{$\begin{array}{l}\text { Transaction Costs } \\
\text { Theory }\end{array}$} & $\begin{array}{l}\text { - Characteristics of economic } \\
\text { relationships: scope and } \\
\text { characteristics of contracts, } \\
\text { frequency of transactions between } \\
\text { supply chain members, expectations } \\
\text { of recurrent transactions between } \\
\text { them. }\end{array}$ & $\begin{array}{l}\text { - Participant observation in } 28 \text { medium- } \\
\text { term planning meetings, and in } 9 \text { design } \\
\text { meetings } \\
\text { - Analysis of long and short-term } \\
\text { production plans ( } 28 \text { weeks), and design } \\
\text { brief } \\
\text { - Project extranet data ( } 8 \text { weeks) and e- } \\
\text { mails }\end{array}$ \\
\hline & $\begin{array}{l}\text { - Other forms of governance: non- } \\
\text { contractual forms of governance } \\
\text { adopted, supply chain members } \\
\text { involved, effectiveness of those } \\
\text { governance forms. }\end{array}$ & $\begin{array}{l}\text { - Participant observation in } 28 \text { medium- } \\
\text { term planning meetings, and in } 9 \text { design } \\
\text { meetings } \\
\text { - E-mails }\end{array}$ \\
\hline \multirow[t]{2}{*}{$\begin{array}{l}\text { Language-Action } \\
\text { Perspective }\end{array}$} & $\begin{array}{l}\text { - Business processes: main } \\
\text { transactions, connections between } \\
\text { different commitment loops, actors } \\
\text { involved, means of communication } \\
\text { used. }\end{array}$ & $\begin{array}{l}\text { - Participant observation in } 28 \text { medium- } \\
\text { term planning meetings, and in } 9 \text { design } \\
\text { meetings } \\
\text { - Project extranet data ( } 8 \text { weeks) and e- } \\
\text { mails }\end{array}$ \\
\hline & $\begin{array}{l}\text { - Interruptions or conflict situations: } \\
\text { main interruptions, frequency and } \\
\text { causes of interruptions, processes } \\
\text { affected, impacts on cooperation } \\
\text { willingness and economic relations. }\end{array}$ & $\begin{array}{l}\text { - Participant observation in } 28 \text { medium- } \\
\text { term planning meetings, and in } 9 \text { design } \\
\text { meetings } \\
\text { - Analysis of long and short-term } \\
\text { production plans ( } 28 \text { weeks), and design } \\
\text { brief } \\
\text { - Project extranet data ( } 8 \text { weeks) and e- } \\
\text { mails }\end{array}$ \\
\hline
\end{tabular}

Table 6 Descriptive factors adopted and sources of evidence

Note: project extranet data includes the number of accesses, frequency of document uploads and downloads, content of electronic documents and drawings

Isatto, E L and Formoso, C T (2011) 'Three theoretical perspectives for understanding inter-firm coordination of construction project supply chains', Australasian Journal of Construction Economics and Building, 11 (3) 1-17 


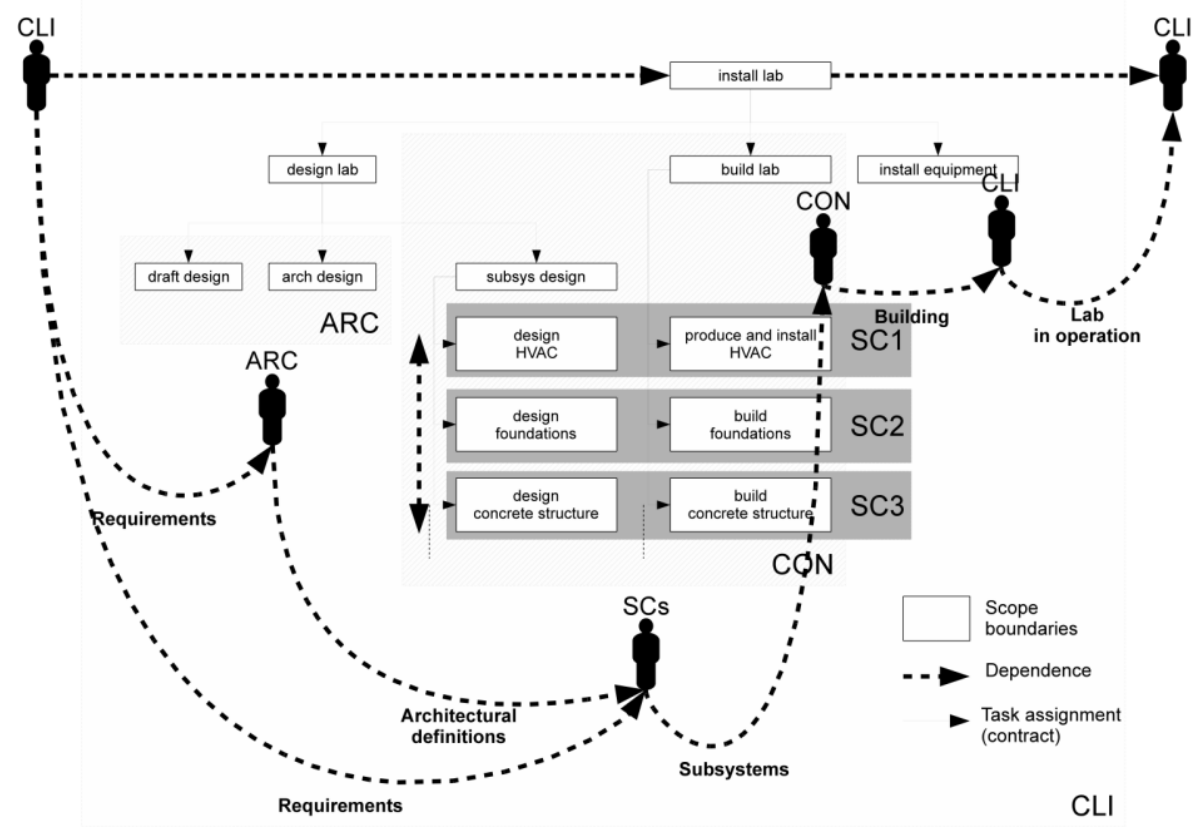

Figure 2 Decomposition of the project into subtasks and dependences between supply chain members

The high specificity and idiosyncratic nature of the task of installing the lab equipment was the reason that led the client organization to assign it directly to an internal department, adopting a unified governance scheme.

No regular meetings between the architect and subcontractors had been planned. It was expected that the architect would send the architectural definitions to the client according to an agreed plan, and client representatives would pass these to the GC, which were responsible for delivering those definitions to subcontractors and production crews. If it was necessary to coordinate the design of any subsystem and the architectural design, it was expected that a subcontractor would informally get in touch with the architect and ask for the necessary definitions.

The coordination of actions among subcontractors on site was managed by the GC by using a production planning and control system that was strongly based on the Last Planner System (Ballard, 2000). One-week short term and one-month look-ahead (medium term) plans were produced in two separate weekly meetings, involving representatives of different production teams. The GC decided to carry out also weekly design coordination meetings, involving members of both production and design teams (including the architect and client representatives), aiming to pass on requests for design definitions to the design team, in order to synchronize design and production inter-related tasks. Such meetings had also the role of enabling conversations among subcontractors regarding the coordination of the design of different subsystems, not only in terms of establishing the necessary commitments of stakeholders but also making compatible sets of design decisions.

The flow of architectural definitions between design and production teams was initially planned to be pushed by the former to the latter. However, as soon as the project started, the client marketing and maintenance departments noticed that some requirements had not been properly considered in the architectural outline design, causing delays in the design process and disruptions in production activities. Consequently, the primary concern of design meetings shifted from the delivery of architectural definitions to the identification of the production needs (e.g. the definition of drawings that needed to be delivered first) and to establish deadlines for the delivery of those design definitions by the architect, which

Isatto, E L and Formoso, C T (2011) 'Three theoretical perspectives for understanding inter-firm coordination of construction project supply chains', Australasian Journal of Construction Economics and Building, 11 (3) 1-17 
resulted in a system of pull coordination between design and production. The size of the batches of design information that were transferred between the members had to be reduced in order to speed up the design process, thus increasing the flow of information between them.

After eight weeks, the project was at risk of serious delay or even complete interruption due to the lack of design definitions, poor coordination among project members, and conflicts between the client and the GC about the project scope and budget. Such difficulties in managing the design process indicated that the adopted contracting scheme was not the most appropriate for that context. The agreement between the client and the general contractor was very rigid in terms of ex-post adaptation. The need for approval of every change by both the client and the GC, plus the need for additional negotiation about the scope of contracts have slowed down the speed of the design processes and increased the risk of project delays. Even the high flexibility of the contracts between the general contractor and the subcontractors was not enough to shield those relationships against the effects of the conflicts between the GC and the client.

In spite of those problems, the highly specific nature of the object of the contract made it very difficult and expensive for any of the parties to interrupt the previous arrangement. As a consequence, the client and the GC agreed to set the original contract aside and to renegotiate previous conditions, taking into consideration the actual context. From one side, the client stopped introducing further changes in the design and delegated the management of the design process to the GC. In turn, the GC agreed with the establishment of a new deadline for project completion (January 2002).

\section{Phase 2}

After renegotiating the contract and freezing some design decisions, the overall governance structure of the project moved from the original classical (client - general contractor) and relational contracting (general contractor - subsystems contractors) schemes to a trilateral one, in which the product development team played the role of a third party in resolving disputes involving technical matters and evaluating performance of relationships between project supply chain members. That migration from two incompatible governance forms to a common governance structure is illustrated in Figure 3. The adoption of the trilateral governance represented an explicit recognition of the possibility of opportunism in the governance structure established to coordinate the relationships between the GC and subcontractors, and of the effect of bounded rationality on the governance structures set up to coordinate the relationships between the client and the GC, and between the client and the architect.

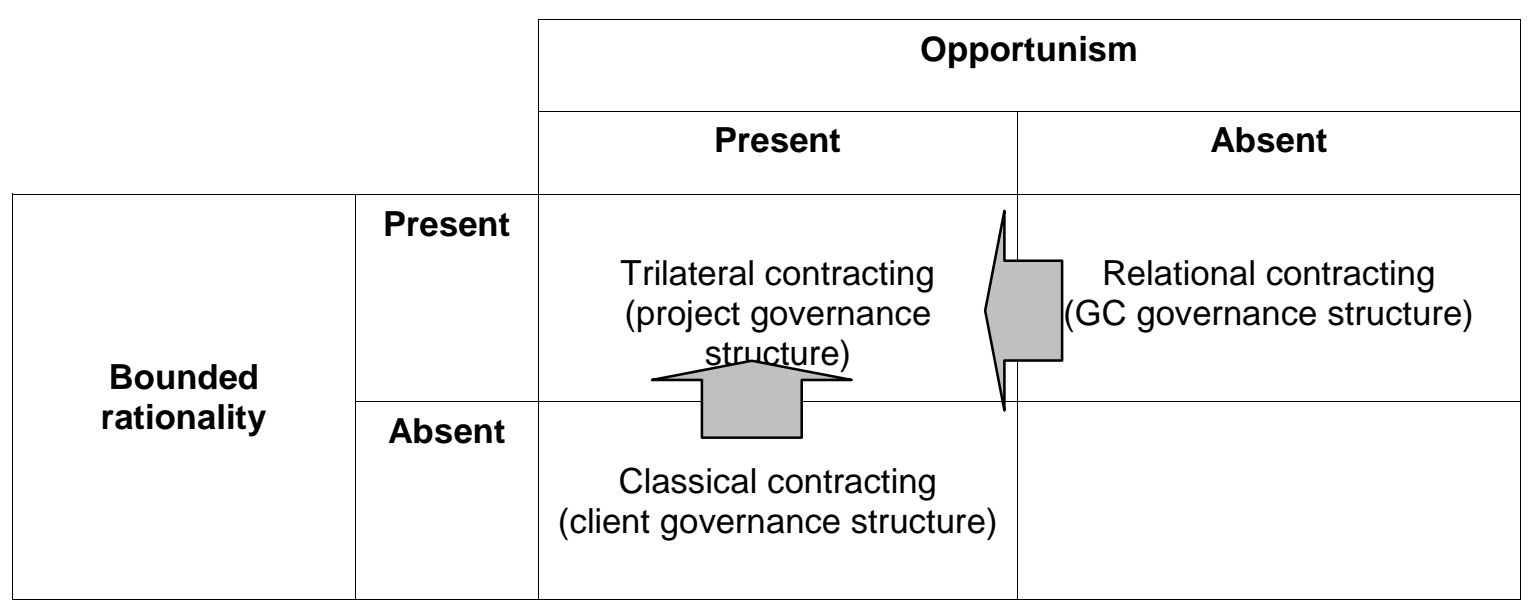

Figure 3 Changes in the governance structure of the construction project supply chain

Isatto, E L and Formoso, C T (2011) 'Three theoretical perspectives for understanding inter-firm coordination of construction project supply chains', Australasian Journal of Construction Economics and Building, 11 (3) 1-17 
As the design process became more complex and difficult to forecast in the long and medium term, design meetings became crucial for the coordination of the actions, since the management of short-term commitments turned out to be the most effective alternative to coordinate the design process and to negotiate changes in the product. This was effectively managed by using the Last Planner System, since there was a direct connection between look-ahead production plans and design weekly plans, prepared at the design coordination meetings. The constraints that were identified in the former had to be addressed in the latter. The dependences between subcontractors were managed mostly as they were using and generating common resources, since information concerned with client requirements and design definitions were used by most of the subsystem designers, and such definitions should be well integrated in the design of the whole product.

Several actions were necessary to manage concurrent dependences. Firstly, the full attendance of designers, general contractor and client representatives to the weekly meetings was enforced in order to make it possible to establish the necessary commitments - more precisely, enabling the request, negotiation and satisfaction phases of commitment loops - and also to negotiate occasional conflicts concerned with design definitions. Secondly, the design team decided to exchange electronic versions of the drawings and documents, thus making the design definitions a shareable and reusable resource. Thirdly, a project extranet was set up to provide simultaneous access to that information for the design team. Fourthly, rules for naming and controlling different versions of production drawings were agreed among the design team, in order to assure the usability of the information to be exchanged among them.

Figure 4 represents the network of commitments that was gradually built by the project supply chain. It represents an important change, since, at the start of the project, commitments were essentially embodied by the contracts, being aligned with the tasksubtask dependences.

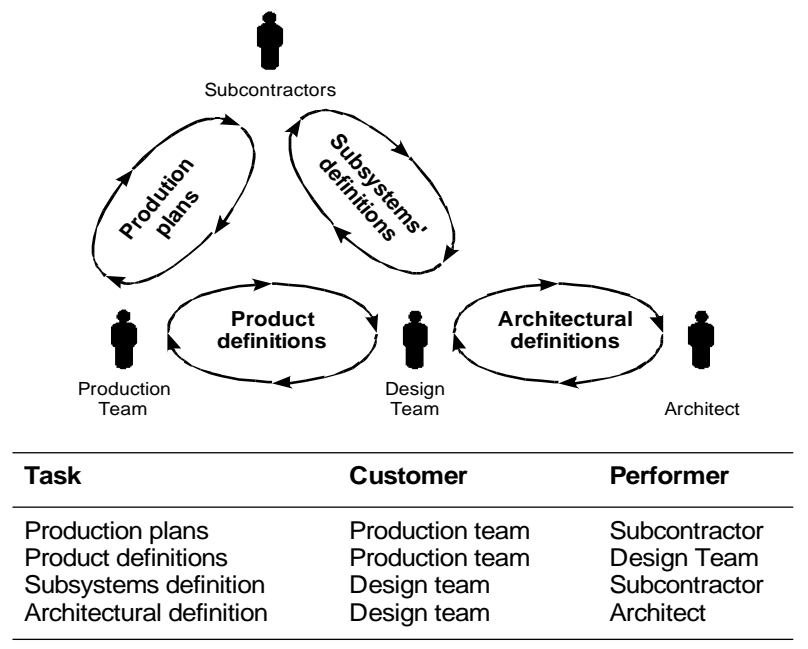

Figure 4 Network of commitments among supply chain members

\section{Discussion}

The contribution of the Theory of Coordination for the analysis of inter-firm coordination is mainly related to the purpose of the supply chain in terms of delivering value to the customer, by addressing how tasks are decomposed and assigned to actors, which dependences arise as a consequence of the previous decisions, and how these dependences are managed. Due to the adaptive and dynamic nature of the construction project supply chains, many of these decisions had to be changed in the course of the project, as shown in Table 7. 


\begin{tabular}{|c|c|c|}
\hline $\begin{array}{l}\text { Descriptive } \\
\text { factors }\end{array}$ & Phase 1 & Phase 2 \\
\hline $\begin{array}{l}\text { Strategy for } \\
\text { breaking down } \\
\text { processes }\end{array}$ & $\begin{array}{l}\text { - Client: specialization by process } \\
\text { - GC: specialization by purpose }\end{array}$ & $\begin{array}{l}\text { - No change due to contractual } \\
\text { bindings }\end{array}$ \\
\hline \multirow[t]{3}{*}{$\begin{array}{l}\text { Dependencies } \\
\text { between supply } \\
\text { chain members }\end{array}$} & $\begin{array}{l}\text { - Task - sub-task dependencies: } \\
\text { (a) Client-architect } \\
\text { (b) Client-GC }\end{array}$ & $\begin{array}{l}\text { - No change due to contractual } \\
\text { bindings }\end{array}$ \\
\hline & $\begin{array}{l}\text { - Main flow dependencies: } \\
\text { (a) From Architect to Client } \\
\text { (b) From Client to GC } \\
\text { (c) From GC to Subcontractors }\end{array}$ & $\begin{array}{l}\text { - Main flow dependencies: } \\
\text { (a) From Architect to GC } \\
\text { (b) From GC to Architect } \\
\text { (c) From Architect to Subcontractors } \\
\text { (d) From Subcontractors to Architect } \\
\text { (e) From Subcontractor to } \\
\text { Subcontractor }\end{array}$ \\
\hline & $\begin{array}{l}\text { - Common resource dependencies: } \\
\text { Among subcontractors }\end{array}$ & $\begin{array}{l}\text { - Common resource dependencies: } \\
\text { Among Architect, GC and } \\
\text { subcontractors }\end{array}$ \\
\hline \multirow[t]{3}{*}{$\begin{array}{l}\text { Structure of the } \\
\text { coordination } \\
\text { system } \\
\text { (coordination } \\
\text { mechanisms) }\end{array}$} & $\begin{array}{l}\text { - Task - sub-task dependencies: } \\
\text { Set up of milestones and deadlines } \\
\text { (plans), and control of deliveries in } \\
\text { regular design coordination } \\
\text { meetings. }\end{array}$ & $\begin{array}{l}\text { Task - sub-task dependencies: } \\
\text { Sharing real-time information by } \\
\text { using a project extranet, and design } \\
\text { and production control through } \\
\text { weekly short and medium-term } \\
\text { planning meetings }\end{array}$ \\
\hline & $\begin{array}{l}\text { - Flow dependencies: } \\
\text { Design information pushed from } \\
\text { the architect to production teams }\end{array}$ & $\begin{array}{l}\text { - Flow dependencies: } \\
\text { Design information pulled at design } \\
\text { coordination weekly meetings based } \\
\text { on the demands of production teams }\end{array}$ \\
\hline & $\begin{array}{l}\text { - Common resource dependences: } \\
\text { Rules, standards and regular } \\
\text { meetings. }\end{array}$ & $\begin{array}{l}\text { - Common resource dependences: } \\
\text { Resources made shareable, rules, } \\
\text { and the establishment of short-term } \\
\text { (one-week) commitments }\end{array}$ \\
\hline
\end{tabular}

Table 7 Project changes concerned with production coordination

However, the assumption that actors are essentially cooperative and that no conflict exists between their goals (Crowston, 1991) greatly constrains the application of TC in the interorganizational context. The role of the Transaction Cost Theory resides exactly on approaching the coordination problem from such perspective, complementing TC by including both economic and behavioral aspects, particularly the ex post aspects of contracts and their effects over their ex ante aspects.

By addressing the governance of the project supply chain, TCT points out the boundaries that limit the space in which cooperation between firms is expected to occur and how the contracts and other governance forms affect this. In the case study, the governance structures that were initially designed by the client and by GC could not cope with the both the effects of high levels of uncertainty and the presence of opportunism. The decision of the construction company in purchasing complete subsystems as engineered-to-order contracts had simplified to a great extent the task of coordinating the activities under its responsibility, since much of the complexity involved in the coordination of dependences between the design, production and installation of each subsystem was transferred to suppliers. However, there was a price for that decision, the loss of ability to coordinate directly much of the process, increasing its dependency on each supplier. This, in turn, resulted in exchanges that involve much more specific and complex assets, which, based on TCT, suggests the adoption of trilateral or bilateral governance structures. In fact, after some negotiations

Isatto, E L and Formoso, C T (2011) 'Three theoretical perspectives for understanding inter-firm coordination of construction project supply chains', Australasian Journal of Construction Economics and Building, 11 (3) 1-17 
between the client and the GC, the trilateral governance was informally adopted by the project supply chain (Table 8).

\begin{tabular}{|c|c|c|}
\hline Descriptive factors & Phase 1 & Phase 2 \\
\hline $\begin{array}{l}\text { Characteristics of } \\
\text { economic relationships }\end{array}$ & $\begin{array}{ll}\text { Client - Architect, Client - GC: } \\
\text { - } & \text { Occasional transaction involving } \\
& \text { highly specific assets } \\
\text { - } & \text { Contractual relationship was } \\
& \text { regarded as isolated from } \\
& \text { previous or future exchanges } \\
\text { - } & \text { Opportunism was anticipated } \\
\text { assuming a foreseeable future } \\
\text { (no uncertainty) } \\
\text { GC - Subcontractors: } \\
\text { - } & \text { Recurrent transactions involving } \\
\text { investments of mixed kind } \\
\text { - } & \text { Contractual relationships were } \\
\text { regarded as a series of } \\
\text { exchanges } \\
\text { Complexity and bounded } \\
\text { rationality were expected to } \\
\text { occur in a context of truth and } \\
\text { mutual cooperation }\end{array}$ & $\begin{array}{l}\text { Client - Architect, Client -GC, } \\
\text { GC - Subcontractors: } \\
-\end{array}$ \\
\hline Governance forms & 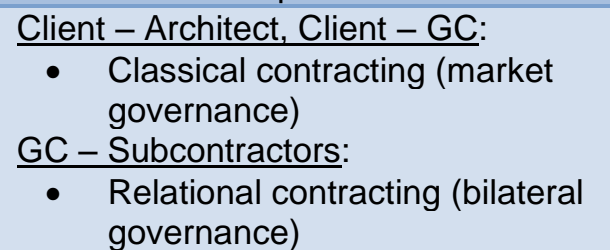 & $\begin{array}{l}\text { Client - Architect, Client - GC, } \\
\text { GC - Subcontractors: } \\
\text { Trilateral governance, } \\
\text { supported by informal } \\
\text { adaptation of existing } \\
\text { contracts }\end{array}$ \\
\hline
\end{tabular}

Table 8 Project changes concerned with economic coordination

The fact that governance structures usually grant some degree of freedom to the parties to act autonomously limits the application of TCT. As pointed out by Grandori (1997), in complex and dynamic environments, such as construction projects, the coordination problem is not limited to regulating exchanges or coordinating dependences among supply chain members, but it is also concerned with governing their collective action. A large number of micro-management decisions cannot be anticipated, and thus are usually left to the operational level in an adaptive manner in order to overcome the project uncertainty (Crowston, 1991; Grandori, 1997).

\begin{tabular}{|l|l|l|}
\hline \multicolumn{1}{|c|}{ Descriptive factors } & \multicolumn{1}{c|}{ Project start } & \multicolumn{1}{c|}{ Project end } \\
\hline $\begin{array}{l}\text { Completeness of } \\
\text { commitment loops }\end{array}$ & $\begin{array}{l}\text { Lack of satisfaction with } \\
\text { commitment loops }\end{array}$ & $\begin{array}{l}\text { Commitment loops completely } \\
\text { fulfilled. }\end{array}$ \\
\hline $\begin{array}{l}\text { Configuration of business } \\
\text { processes as a network of } \\
\text { commitments }\end{array}$ & $\begin{array}{l}\text { Commitment loops aligned with } \\
\text { contracts (vertical coordination) }\end{array}$ & $\begin{array}{l}\text { Commitment loops aligned with } \\
\text { flow dependences (horizontal } \\
\text { coordination) }\end{array}$ \\
\hline
\end{tabular}

Table 9 Project changes concerned with social coordination

The main contribution of the Language/Action Perspective is to explain how managerial processes that occur in the inter-firm context are coordinated even when little control exists over the sequence and content of the activities. Additionally, LAP suggests how to manage the collective action of supply chain members within the space of possibilities that is limited by the same boundaries. In the case study, LAP explained how the Last Planner System was used to manage the collective action inside the space of possibilities of action delimited by governance structures, evidencing the imminence of breakdowns due to the 
incompleteness of commitment loops or the poor connection of commitments. Table 9 presents the main changes related to the social coordination of supply chain.

Table 10 summarizes the contributions of each theoretical approach, emphasizing the complementarities that exist between them. The connection between TC and TCT relies on the idea of assignments that happen in the economic environment, bridging the gap between the coordination of production and economic flows. The combined use of LAP and TCT explains how coordination processes occur in the space of possibilities that is defined by contracts and other forms of governance that are responsible for defining the expected boundaries of cooperation among the firms. The connection between TC and LAP is clearly due to the fact that the commitment loops are essentially a coordination mechanism that is used to guarantee the accomplishment of a task. Nonetheless, their complementarities comes from the fact that the TC emphasizes the dependences among tasks and the way tasks are decomposed and assigned, and gives little attention to the design of the information system that will support the coordination, while the LAP focus precisely on the essential aspects related to information systems in order to coordinate actions among people through the management of commitments. Moreover, LAP also extends TC by including situations of execution by demand, in which individuals act in response to a demand of other individuals that depend on the outputs of their tasks.

\begin{tabular}{|c|c|c|c|}
\hline \multirow{2}{*}{ Relationship } & \multicolumn{3}{|c|}{ Role } \\
\hline & TCT & TC & LAP \\
\hline TCT and LAP & $\begin{array}{l}\text { TCT explains how to } \\
\text { define a space of } \\
\text { possibilities for } \\
\text { decision-making } \\
\text { through contracts and } \\
\text { other governance } \\
\text { structures. }\end{array}$ & $x$ & $\begin{array}{l}\text { LAP explains how to } \\
\text { coordinate collective } \\
\text { action in the space of } \\
\text { possibilities defined by } \\
\text { governance structures } \\
\text { through the managed of } \\
\text { commitments. }\end{array}$ \\
\hline TCT and TC & $\begin{array}{l}\text { TCT explains how to } \\
\text { coordinate transactions } \\
\text { among supply chain } \\
\text { members by the } \\
\text { management of their } \\
\text { economic interests. }\end{array}$ & $\begin{array}{l}\text { TC explains how } \\
\text { tasks must be } \\
\text { decomposed and } \\
\text { how to manage the } \\
\text { connections } \\
\text { (dependences) } \\
\text { among them. }\end{array}$ & 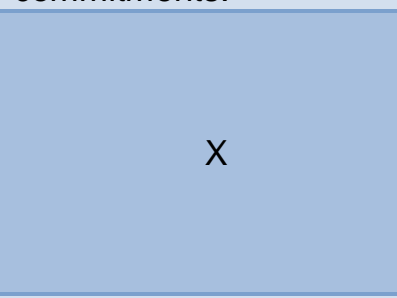 \\
\hline TC and LAP & $x$ & $\begin{array}{l}\text { TC explains how to } \\
\text { define the outcomes } \\
\text { of business } \\
\text { processes and which } \\
\text { tasks need to be } \\
\text { performed } \\
\text { collectively. }\end{array}$ & $\begin{array}{l}\text { LAP explains how to } \\
\text { coordinate the execution } \\
\text { of tasks among different } \\
\text { stakeholders through the } \\
\text { establishment of a } \\
\text { network of commitments. }\end{array}$ \\
\hline
\end{tabular}

Table 10 Complementarities between TC, TCT and LAP

\section{Conclusion}

This article has pointed the limitations and complementarities of three theoretical approaches in describing the inter-firm coordination of construction project supply chains. Based on the literature review, the Theory of Coordination, the Transaction Cost Theory, and the Language-Action Perspective were chosen for explaining inter-firm coordination from three different perspectives, which are related to the product, financial and information flows, respectively.

The Theory of Coordination has been used to describe the organizational aspects of the supply chain, addressing the problem of coordination from the perspective of managing the resource dependences that occur between stakeholders. The Transaction Cost Theory helps

Isatto, E L and Formoso, C T (2011) 'Three theoretical perspectives for understanding inter-firm coordination of construction project supply chains', Australasian Journal of Construction Economics and Building, 11 (3) 1-17 
to understand how transactions frequency and asset specificity in a construction project can influence the most adequate kind of governance structure to be adopted in each situation, which greatly affect the cooperation among the members of the construction project supply chain. Finally, the Language-Action Perspective explains how cooperation can be maintained through the establishment and successful accomplishment of networked commitments among supply chain members, helping to analyze and design more appropriate information systems for managing construction project supply chains.

The use of this set of theoretical approaches is especially valuable in complex construction projects. Considering that contracts are themselves broad commitments, as uncertainty and complexity rise, project managers face an increasing difficulty to coordinate the project supply chain only by managing contracts, which will in turn result in delegating a larger share of the coordination process to other stakeholders at operational levels. As individuals or firms are awarded more autonomy, the overall coordination burden grows, demanding organizational structures that are able to manage commitment loops in terms of their integrity and effective completion.

The discussion on the role of three theoretical approaches, presented in this paper, represents an early step towards the development of a multiple theoretical framework in this field. Therefore, much work is still needed for developing a unified theory on the coordination of construction project supply chains. Further investigation on the underpinning assumptions of each theoretical approach is necessary, in order to assess to which extend they could form a unified theory. It is not clear yet if the three approaches are commensurable or whether they need to be commensurable and at what level. More work is also needed on establishing the boundaries of this set of theoretical approaches, in relation to other perspectives proposed in the literature.

\section{References}

Axelrod, R. (1984) The Evolution of Cooperation, New York: Basic Books

Ballou, R., Gilbert, S. M. and Mukherjee, A. (2000) 'New managerial challenges from supply chain opportunities', Industrial Marketing Management, 29, 7-18

Ballard, G. (2000) The Last Planner System of Production Control, Ph.D. thesis, Faculty of Engineering, The University of Birmingham

Bresnen, M. (1996) 'An organisational perspective on changing buyer-supplier relations: A critical review of the evidence', Organisation, 1 (3) 121-146

Cherns, A. and Bryant, D. (1983) 'Studying the clients' role in construction management', Construction Management and Economics, 177 (2)

Choi, T.Y., Dooley, K.J. and Rungtusanatham, M. (2001) 'Supply networks and complex adaptive systems: control versus emergence', Journal of Operations Management, 19, 351366

Christopher, M. (2000) 'The agile supply chain: Competing in volatile markets', Industrial Marketing Management, 29, 37-44

Croom, S., Romano, P. and Giannakis, M. (2000) 'Supply chain management: an analytical framework for critical literature review', European Journal of Purchasing \& Supply Management, (6), 67-83

Crowston, K. (1991) Towards a Coordination Cookbook: Recipes for Multi-Agent Action, Ph.D. Dissertation, Massachusetts Institute of Technology - Sloan School of Management

Crowston, K. and Osborn, C.S. (2003) 'A coordination theory approach to process description and redesign', In T. W. Malone, K. Crowston, and G. Herman (Ed.), Tools for Organizing Business Knowledge: The MIT Process Handbook. Cambridge, MA, MIT Press

Denning, P.J. and Medina-Mora, R. (1995) 'Completing the loops', Interfaces, 25, 42-57

Isatto, E L and Formoso, C T (2011) 'Three theoretical perspectives for understanding inter-firm coordination of construction project supply chains', Australasian Journal of Construction Economics and Building, 11 (3) 1-17 
Flores, F. (1982) Management and communication in the office of the future, Ph.D. Dissertation, Graduate Division of the University of California

Gigerenzer, G. and Selten, Reinhard, (2001) Bounded Rationality: The Adaptive Toolbox, Cambridge Mass: MIT Press

Grandori, A. (1997) 'An organizational assessment of interfirm coordination modes', Organization Studies, 18 (6), 897-925

Håkanson, H. and Ford, D. (2002) 'How should companies interact in business networks?', Journal of Business Research, 55, 133-139

Johnson, P. (1995) 'Supply chain management: the past, the present and the future', Manufacturing Engineer, 74 (5)

Kuhn, T.S. (1970) The Structure of Scientific Revolutions, University of Chicago Press Chicago

Macneil, I. R. (1978) 'Contracts: Adjustment of long-term economic relations under classical, neoclassical and relational contract law', Northwestern University Law Review, 72, 854-902

Macomber, H. and Howell, G. (2003) 'Linguistic action: Contributing to the theory of lean construction', In Proceedings of the 11th Annual Meeting of the International Group for Lean Construction. Blacksburg, Virginia, 1-10

Malone, T. W. and Crowston, K. (1994) 'The interdisciplinary theory of coordination', ACM Computing Surveys, 26, 87-119

March, J. G. and Simon, H. A. (1958) Organizations. John Wiley and Sons, New York

O'Brien, W., London, K. and Vrijhoef, R. (2004) 'Construction supply chain modelling: A research review and interdisciplinary research agenda', ICFAI Journal of Operations Management, 3 (3), pp. 64-84

Otto, A. and Kotzab, H. (2003) 'Does supply chain management really pay? Six perspectives to measure the performance of managing a supply chain', European Journal of Purchasing \& Supply Management, (144), 306-320

Tan, K.C. (2001) A framework of supply chain management literature, European Journal of Purchasing \& Supply Management, (7), 39-48

Thompson, J.D. (1967) Organizations in Action: Social Science Bases of Administrative Theory., New York, NY: McGraw-Hill

Simon, H. A. (1961) Administrative Behavior, $2^{\text {nd }}$ ed, New York: Macmillan

Stadtler, H. (2005) Supply Chain Management and Advanced Planning: Concepts, Models, Software and Case Studies, $3^{\text {rd }}$ ed, Berlin; New York: Springer

van Reijswoud, V.E. and Dietz, J.L.G. (1999) DEMO Modelling Handbook. Delft, Delft University

Vrijhoef, R., Koskela, L. and Howell, G. (2001) 'Understanding construction supply chains: An alternative interpretation', In Proceedings of the $9^{\text {th }}$ International Group of Lean Construction (IGLC-9). Singapore, National University of Singapore

Vrijhoef, R., Koskela, L. and Voordijk, H. (2003) 'Understanding construction supply chains: a multiple theoretical approach to inter-organizational relationships in construction', In Proceedings of the $11^{\text {th }}$ International Group of Lean Construction Conference (IGLC-11). Blacksburg, USA: Virginia Polytechnic Institute and State University

Williamson, O.E. (1985) The Economic Institutions of Capitalism, New York: The Free Press

Winograd, T. and Flores, F. (1986) Understanding Computers and Cognition: A New Foundation for Design, Boston, Addison-Wesley 